Vol. 4, No. 1, 2018

Mykola Vorobyov ${ }^{1}$, Denis Prokopenko ${ }^{2}$

${ }^{1}$ Department of Applied Mechanics, Ivano-Frankivsk National University of Oil and Gas,

15, Karpatska Str., Ivano-Frankivsk, Ukraine, E-mail: :teormech@nung.edu.ua

${ }^{2}$ Department of Applied Mechanics, Ivano-Frankivsk National University of Oil and Gas,

15, Karpatska Str., Ivano-Frankivsk, Ukraine, E-mail: Deniss_2005@ukr.net

\title{
HYDRAULIC PUMP BASED ON THE ROLAMITE MECHANISM
}

\author{
Received: February 15, 2018 / Revised: May 07, 2018 / Accepted: June 26, 2018
}

(C) Vorobyov M., Prokopenko D., 2018

\begin{abstract}
When designing pumping equipment the question arises not only of the improvement of the existing types but also the search for a new principle of uniting the supporting elements with the elements of the formation of the working cameras of the pump. The purpose of the work is to provide a substantiation of the possibilities and expediency of designing a de-axial pump based on the Rolomite mechanism. Conditions ensuring the efficiency of the mechanism are considered on the basis of a specific hydraulic pump; the principle of inlet and outlet windows placement is justified. Analytical calculation of camera areas with the help of the created model in SolidWorks is provided and the coefficient of liquid compression is determined. The graphs of changing the areas of large and small cameras are presented.

The use of an electromagnet as a drive makes it possible to transfer the rotation into a closed space, which makes it possible to abandon bearings, seals, and also significantly simplifies the technological process of pump elements manufacturing. The flexible tape allows reducing the slip friction and getting a separate camera, which makes it possible to pump two substances at a time. There is also a process of liquid magnetization in the pump, which reduces the corrosion of metal elements of the pump and the pipelines. Considering the benefits of these types of mechanisms, there is the prospect of their further research and implementation.
\end{abstract}

Keywords: hydro pump, Rolamite mechanism, rolling body, electromagnetic drive.

\section{Introduction}

Today, almost no industry can do without the use of pumps and pumping systems of various structures, although until recently they were mainly used for the purpose of taking, pumping and supplying exclusively liquid. Even before our era, the first pumps were invented precisely for this purpose, which were mainly used for extinguishing fires. The twenty-first century, with the accelerated development of high-tech industries, puts new demands on designers of pumping equipment, since there is an urgent need to transport not only water, but also other liquids, different in their physicochemical properties and characteristics, and in particular oil and petroleum products. Therefore, actual requirements for the improvement of pumping equipment become relevant.

\section{Problem Statement}

Quite often, when designing a particular type of pump, the designer chooses the already existing option and the entire subsequent design process is reduced to a certain improvement of a particular type of pump. It is necessary to search for a new principle of uniting the supporting elements with the elements of formation of the working cameras of the pump.

\section{Review of Modern Information Sources on the Subject of the Paper}

Due to the simplicity and reliability of the work, pumps have been widely used in various industries. There are many types and varieties of pumps. Consider volumetric rotary pumps, acting on the principle of squeezing out. These pumps work by changing the volume of the working camera. The fluid, which is 
being pumped up, fills the working camera, and then it is pushed out of it into the injection pipeline. The working camera is a temporarily closed space, which is limited to movable and stationary parts of the pump and changes its volume during the pump operation. Movement of the parts provides a change in the volume of the working camera and, as a consequence, pumping of the liquid.

Efficiency coefficient for these pumps can be divided into two components and written as follows:

$$
\eta_{3}=\eta_{1} \cdot \eta_{2}
$$

where $\eta_{3}$ is a general efficiency coefficient of a rotor pump; $\eta_{1}$ is a hydraulic component of the efficiency coefficient; $\eta_{2}$ is a mechanical component of the efficiency coefficient.

For example, for a gear pump, a hydraulic component is affected by fluid losses due to radial gaps between the cylindrical surfaces of the body recesses and the outer surfaces of the teeth gears, as well as through the gap between the teeth. The value of the radial gap is determined by the possible size of the gap in the bearings and their non-alignment, as well as the magnitude of the eccentricity of the gears in the blocks of the case. The given losses comprise about $75-80 \%$ of total losses in the pump [1]. Traditional methods to combat these losses [2] lead to complications of pump designs.

In addition to hydraulic losses, the value of the pump's efficiency is influenced by its mechanical part, namely: type of bearings, seal construction, accuracy and treatment of friction surfaces. The complexity of the design (and, consequently, high cost) is due to the need for thorough sealing of the suction and exhaust volumes (cameras) of the pump, fitting and grinding of the contact parts, high requirements for the quality of assembling and operation.

In the case of a gapless clutch there is undesirable compression of the fluid, which causes large loads on the gears and leads to increased wear of the teeth and overheating of the shaft and bearings. There are ways to combat compression [2], but this further complicates the design.

Another disadvantage of rotary pumps is high requirements for the fluid to be pumped, since the tightness of most rotary pumps is achieved by tight fitting of moving parts to the fixed ones. To ensure the durability of sealing elements, it is necessary that the fluid to be pumped does not create abrasive action on the part (for example, the sand, falling between the teeth, increases the slip of the teeth profiles, which accelerates their wear).

In order to avoid the negative influence of these disadvantages on the qualitative parameters of the existing rotary volumetric hydraulic pumps, we have proposed a fundamentally new rotary hydraulic pump [4]. It uses the advanced Rolamite mechanism with an electromagnetic drive.

An American inventor Donald Wilkes has patented the "Rolamite" mechanism [3]. This mechanism consisted of two rollers held on the track, on the opposite sides of the S-shaped tape of elastic metal, along which the rollers move, so the group moves along with them. Since the tape and rollers move at the same speed, there is no slip or drag between them, and therefore there is practically no friction. The device is so versatile that it can function as a switch, valve, pump, fuse, thermostat, amplifier, coupling, speed change device, brake, pressure sensor, electromagnet, fire alarm. [3]. As a result of the experiments, it was found that the beryllium copper strips used in Rolamite were so strong that they showed no signs of metal fatigue after 1000,000 bends.

During further experiments, it was discovered that, due to the tension of the flexible tape, the slip of the rollers is practically eliminated, providing the least frictional losses with a coefficient of less than 0.0005 , i.e., slip friction turns into almost pure rolling without the use of lubrication [8].

The paper [11] notes that frictional losses are significantly reduced when using Rolamite based devices. Friction losses in such devices are much less than alternative, because they do not contain slippery surfaces - identical areas of the surface of the roller and the tape are always in contact. The design of many Rolamite devices eliminates the use of lubricants, and therefore they are especially useful in places where high vacuum or high temperature changes make it difficult to find suitable lubricants.

Small friction coefficient and various combinations that can be made by changing the size of the rollers and tapes, have stipulated application of this mechanism not only in technology but in human life. The paper [12] describes the methods of applying the Rolamite principles to create upper extremity prostheses, which can restore the important function of the human hand. 
The paper [13] describes the application of this mechanism in dentistry. Insignificant frictional force makes it possible to create different variations of prosthetics.

In the former Soviet Union, mechanisms of this type were not often mentioned. The scientists of the Scientific and Research Laboratory "Vibrotechnics" of Kaunas Polytechnic Institute were among the first in the USSR to begin the investigation of these mechanisms [9]. During the research, it was found that due to the high tension of the tape, significant normal forces between the tape and the rollers practically exclude slipping [9].

For the most part, pumps that were built on the Rolamite mechanism were of a parietal type. For example, an author's certificate [10] shows one of these pumps. Its disadvantages are low reliability due to relatively poor adhesion of a thin flexible strain strip with a vibrating surface of the drum, which is also complicated by a relatively small surface of contact between the tape and the drum and, consequently, the reduction of the efficiency coefficient and the power of the pump.

The principle of using this mechanism in two mutually perpendicular planes is interesting [14].

The mechanisms, in which free space, formed between working and distributing rollers, began to be used, can be called a new group of such mechanisms. One of such mechanisms is the mechanism of a gas meter [7]. The invention refers to gas control devices and can be used to control fluid flow. Its moving part is made in the form of three hollow rollers, separated by an endless elastic band. Distributing rollers have the opportunity to interact with the axle of the body, and the working ones - with its inner surface. Each of the working rollers is made with an external radius, four times smaller than the radius of the inner surface of the body. The constant contact of the rollers with the body and the endless tape allows the cylindrical generators to safely cut off the guaranteed measured volume of the substance, which provides reduction of the measurement error.

\section{The Goal and Objectives of Research}

The goal is to substantiate the possibilities and feasibility of using a de-axial Rolamite mechanism as the basis for a fundamentally new bulk type hydraulic pump.

The objectives are as follows: 1) establishment of conditions ensuring the efficiency of the mechanism; 2) substantiation of rational placement of inlet and outlet windows; 3) project definition of the cyclic calculated volume of the pumped liquid; 4) determination of the liquid volume based on a specific example of the pump and the amount of the liquid compression.

\section{Presenting the Main Material}

Suppose that $\mathrm{n}_{1}$ peripheral rollers, that do not touch each other, are in constant contact: externally with a curved cylindrical surface, and from the opposite sides with the same number of $n_{2}$ rollers, which have the ability to continuously contact with the outer surface of the spike, located eccentrically with respect to the axis of a concave cylindrical surface, and with the rollers $\mathrm{n}_{1}$ dividing the peripheral rollers below their axes.

If any roller moves along the surface of a fixed spike or the fixed concave cylindrical surface, then as a result of the closure of the kinematic chain, all other rollers will start moving by sliding.

We separate the group of $n_{1}$ rollers by a pre-stretched infinite elastic thin ribbon from the group of $n_{2}$ rollers in the zone of their adjoining (Fig. 2) and specify a plane-parallel motion of one of them. Then the group of $\mathrm{n}_{1}$ rollers will roll over the stationary inner surface of the peripheral cylindrical surface, and group $\mathrm{n}_{2}$ - on the outer surface of the spike. Each of the rollers will also roll with a slight slip on the specified tape. In the given paper [3] it is proved that the coefficient of friction of this slip will be about 0.0005 , and the efficiency coefficient of such mechanism is approaching 1.

The advantages of the obtained mechanism as a base for the pump are the possibility to obtain the movement of the links in the closed space, the regular overlap with the rollers of the input and output windows located on the stationary rolling surfaces, the formation of cameras between the stationary rolling surfaces and the rollers, separated by a tape, with slight slip. To increase the volume of working cameras, this mechanism allows you to limit the number of rollers $n_{1}=n_{2}=3$. 
The proposed improvement of the Rolamite mechanism [4] consists of the eccentric arrangement of fixed rolling bearings (Figs. 2 and 3), which enables not only to get rid of unnecessary technological supporting elements (for example, bearings), but also to simplify the technological process of manufacturing this construction both in terms of technological operations, and in terms of manufacturing precision.

The working elements in the new pump are working 6 and distributing rollers 5 made of dielectric material, except for one working roller 8 made of ferromagnetic material and separated by an infinite dielectric elastic thin ribbon 4 . The distributing rollers are provided with the ability to interact with a fixed spike 7 , which is eccentrically fixed in the body 2 , and the working rollers are rolling on its internal surface. Permanent contact of working rollers with a cylindrical surface, and the distributing ones with the axle of the body and the coverage of the rollers with a tape, makes it possible to avoid liquid losses due to the presence of a radial gap, which allows increasing the productivity of the pump.

The proposed hydraulic pump runs as follows. When the drive 1 is activated, there is a running magnetic field [5]. It forces the ferromagnetic working roller 8 to roll along the inner cylindrical guide line of the body 2. Due to the kinematic connection of this roller with other rollers, with the help of tape 4, they will begin rolling: the working rollers - along the cylindrical surface of the body 2 , and the distributing ones - along the spike 7. Since the spike 7 is made eccentric, the volume between rollers will start to change. In this case, the volume of the liquid, between the two adjacent working 6 and distributing 5 rollers, will begin to decrease from the injection cavities to the suction cavities. In the suction zone, the volumes that increase between the rollers are filled with the liquid that under the atmospheric pressure gets from the tank through holes B and $\mathrm{b}$. When the volume between the rollers is reduced, the liquid from them will be pushed into the pressure line through windows $\mathrm{C}$ and c. Fig. 1 shows the scheme of inlet and outlet windows placement.

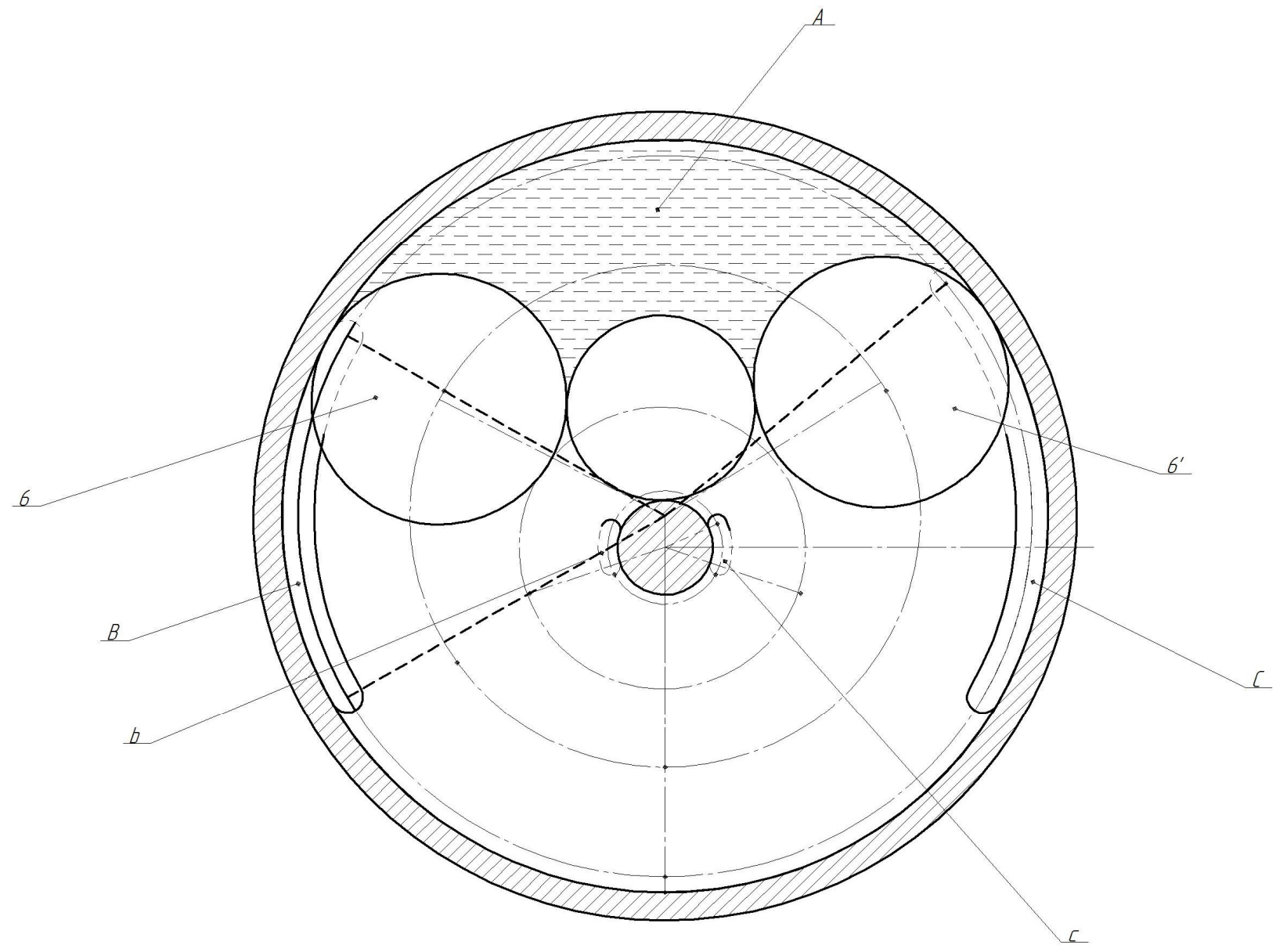

Fig. 1. Scheme of inlet and outlet windows placement 
The windows are arranged in such a way that when the roller 6 closes the window B, that is, it cuts off a certain portion of the liquid (cavity A), the roller 6 opens the exhaust window and as a consequence the liquid from the cavity A is fed further into the pipeline. This solution prevents the flow of fluid from one cavity to another. Thus, the rollers simultaneously play the role of valves.

The peculiarity of this design is that this pump allows (if necessary) to work simultaneously with two different types of liquid, which is achieved through the system of two independent working cameras that are formed by working and distributing rollers (camera 1), distributing rollers and a spike (camera 2).

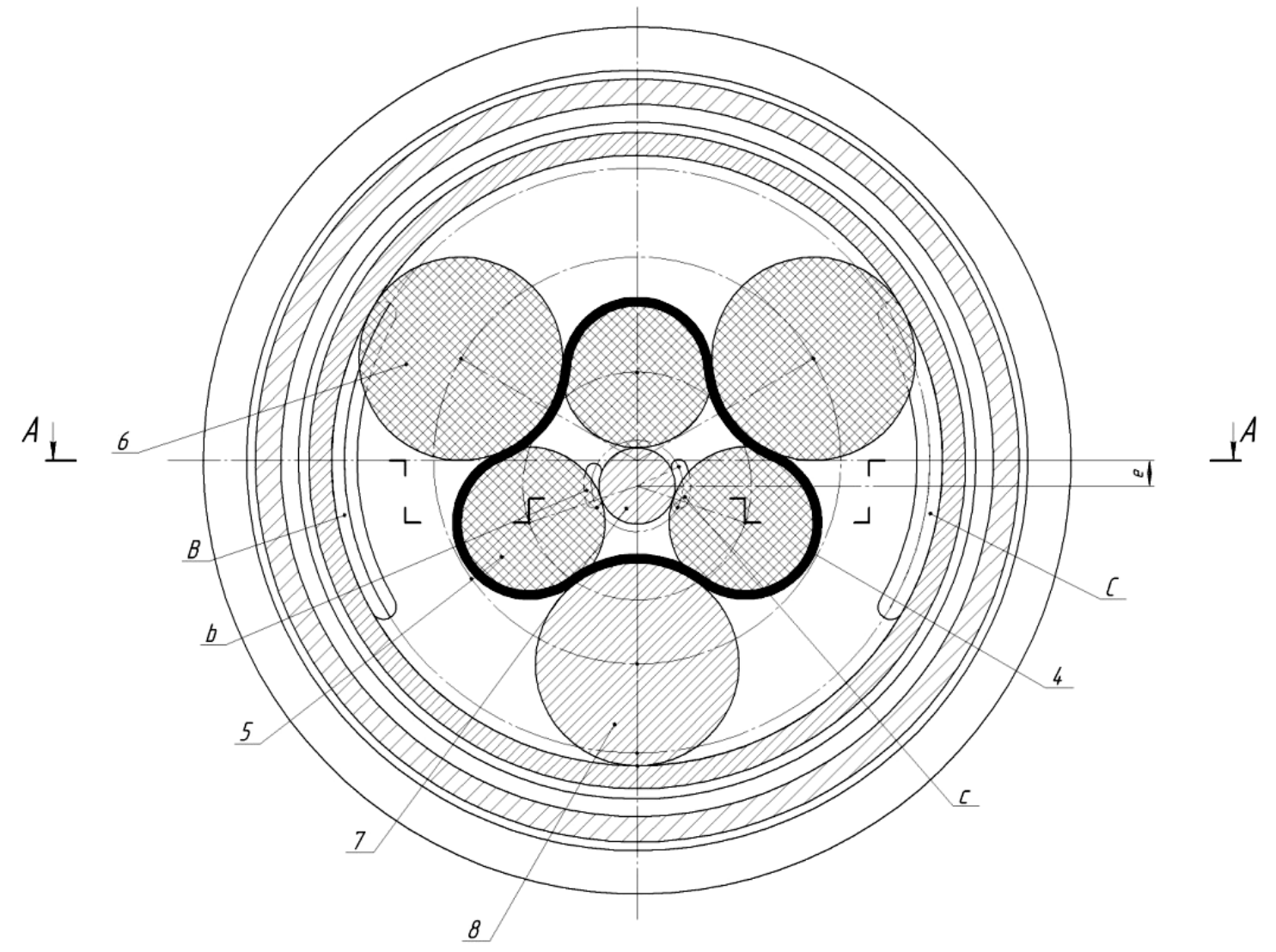

Fig. 2. Front view of the pump

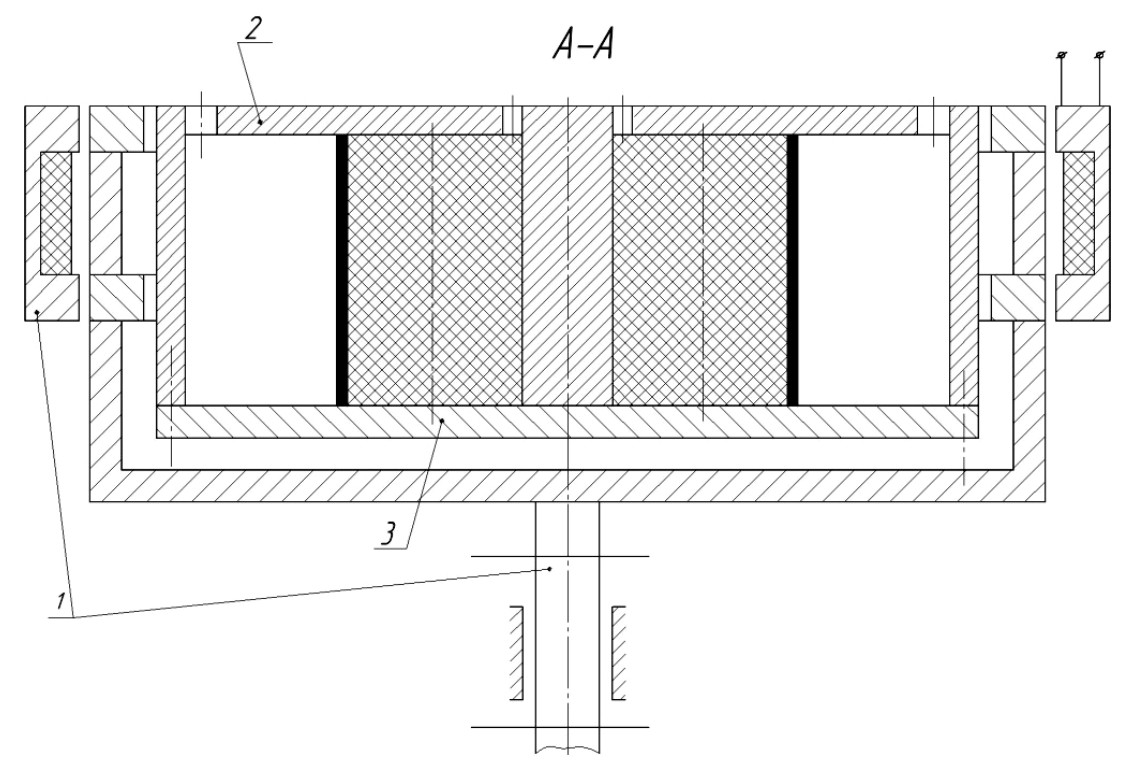

Fig. 3. Section A-A 
In the electromagnet used as a drive, performed on the principle of the rolling rotor [5], when the current is applied, a running magnetic field affects a ferromagnetic roller. This allows: 1) rolling bodies to perform a dual function - as rolling bearings and cutting off a portion of the liquid; 2) receive a rotary motion of working elements in a closed space, which solves the problem of sealing the working area and avoiding the loss of instantaneous flow due to the fluid leakage in radial gaps.

The area of the change of working cameras formed by working and distributing rollers is determined as follows (Fig. 4).

From the triangle $O O_{1 t 1} O_{10}$ you can determine the angle $\alpha$

$$
\alpha=\frac{180^{\circ}-\omega t^{\circ}}{2},
$$

where $\omega t$ is the angle of rotation of the rollers from the initial position;

and the length of the side $O_{1 t 1} O_{10}$

$$
O_{1 t 1} O_{10}=\frac{O O_{1 t 1} \sin \omega t}{\sin \alpha},
$$

where

$$
O O_{1 t 1}=R-R_{1} \text {. }
$$

From the triangle $O_{e} O_{1 t 1} O_{10}$ we have the length of the side $O_{1 t 1} O_{e}$

$$
O_{1 t 1} O_{e}=\sqrt{\left(O_{1 t 1} O_{10}\right)^{2}+\left(O_{e} O_{10}\right)^{2}-2 \cdot\left(O_{1 t 1} O_{10}\right) \cdot\left(O_{e} O_{10}\right) \cdot \cos \alpha},
$$

where

$$
O_{e} O_{10}=R-R_{1}-e
$$

and the angle $\gamma$

$$
\gamma=\arcsin \frac{\left(O_{1 t 1} O_{10}\right) \sin \alpha}{\left(O_{1 t 1} O_{e}\right)} .
$$

Consider the triangle $O_{e} O_{2 t} O_{1 t 1}$ to determine the following angles:

$$
Q_{1 t}=\arccos \frac{\left(O_{2 t} O_{e}\right)^{2}+\left(O_{1 t 1} O_{e}\right)^{2}-\left(O_{1 t 1} O_{2 t}\right)^{2}}{2 \cdot\left(O_{2 t} O_{e}\right) \cdot\left(O_{1 t 1} O_{e}\right)},
$$

where

$$
\begin{gathered}
\left(O_{e} O_{2 t}\right)=R_{2}-e, \\
\left(O_{1 t 1} O_{2 t}\right)=R_{2}+R_{1}, \\
\delta_{1}=\arcsin \frac{\left(O_{1 t 1} O_{e}\right) \sin Q_{1 t}}{\left(O_{1 t 1} O_{2 t}\right)}, \\
\beta=180^{0}-Q_{1 t}-\delta_{1} .
\end{gathered}
$$

From the triangle $O_{e} O_{2 t} \mathrm{O}$ the length of the side $O_{1 t 1} O_{e}$ is defined:

$$
O_{2 t} O=\sqrt{\left(O_{e} O\right)^{2}+\left(O_{e} O_{2 t}\right)^{2}-2 \cdot\left(O O_{e}\right) \cdot\left(O_{e} O_{2 t}\right) \cdot \cos \Delta},
$$

where

$$
\begin{gathered}
O_{e} O=e, \\
\left(O_{e} O_{2 t}\right)=R_{2}+r, \\
\Delta=180-\left(Q_{1 t}+\gamma\right) ;
\end{gathered}
$$

and the angle $\delta_{2}$

$$
\delta_{2}=\arcsin \frac{\left(O O_{e}\right) \sin \Delta}{\left(O O_{2 t}\right)}
$$




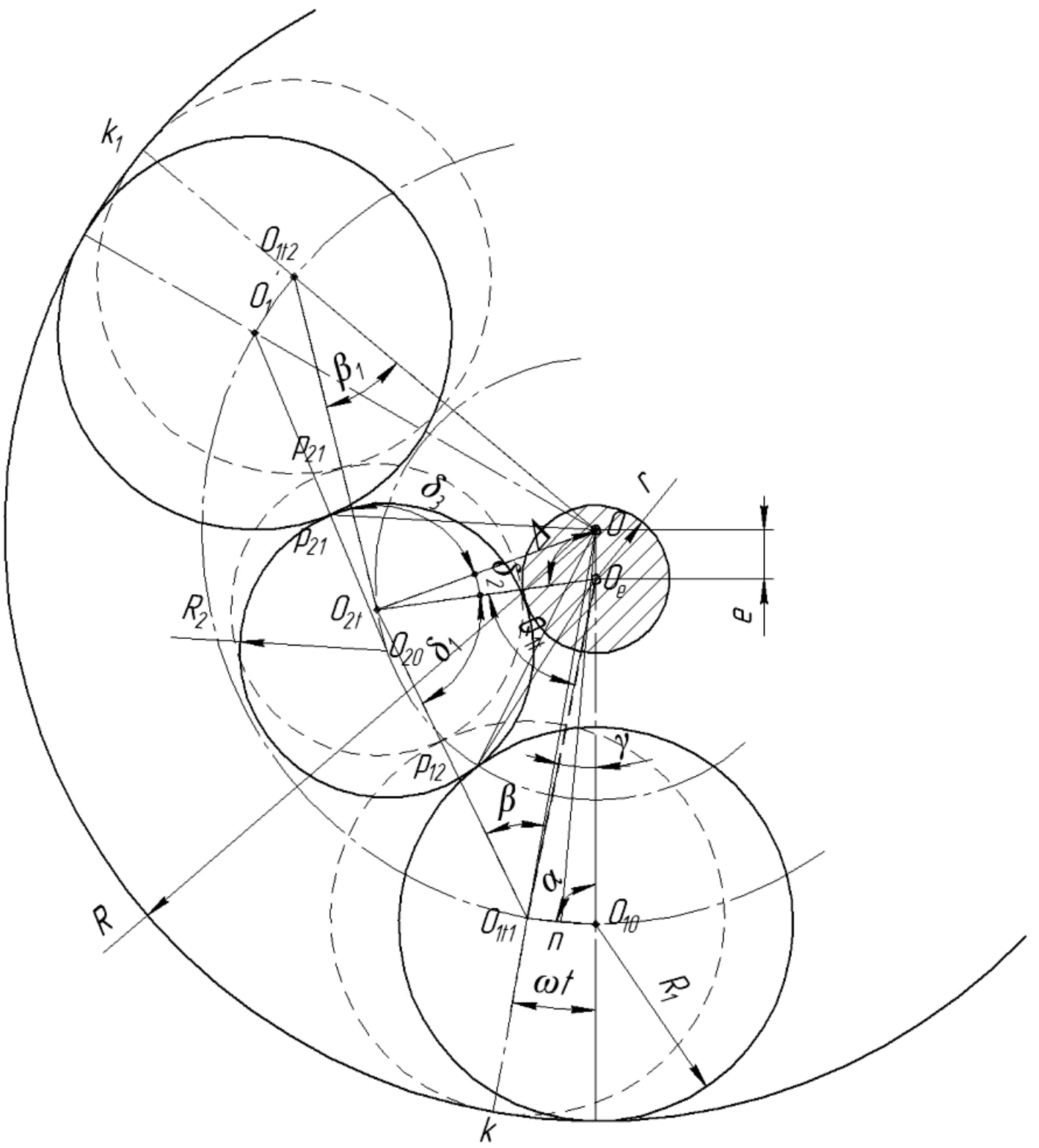

Fig. 4. Scheme for determining the area of working cameras

Finally, from the triangle $O O_{2 t} O_{1 t 2}$ we get:

$$
\beta_{1}=\arccos \frac{\left(O_{1 t 2} O_{2 t}\right)^{2}+\left(O_{1 t 1} O\right)^{2}-\left(O_{2 t} O\right)^{2}}{2 \cdot\left(O_{1 t 2} O_{2 t}\right) \cdot\left(O_{2 t} O\right)},
$$

where

$$
\begin{aligned}
& O_{1 t 1} O_{2 t}=R_{2}+R_{1}, \\
& O_{1 t 2} O_{2 t}=R-R_{1},
\end{aligned}
$$

the angle $\delta_{3}$

$$
\delta_{3}=\arcsin \frac{\left(O O_{1 t 2}\right) \sin \beta_{1}}{\left(O O_{2 t}\right)} .
$$

The found angles give an opportunity to determine the area of the sectors as follows:

$$
S_{1}=S_{k_{1} O k}=\pi R^{2} \frac{120^{\circ}}{360^{\circ}} ;
$$




$$
\begin{gathered}
S_{2}=S_{p_{12} O_{1 t 1} k}=\pi R_{1}^{2} \frac{180^{\circ}-\beta^{\circ}}{360^{\circ}} ; \\
S_{3}=S_{p_{21} O_{1 t 2} k_{1}}=\pi R_{1}^{2} \frac{180^{\circ}-\beta_{1}^{\circ}}{360^{\circ}} ; \\
S_{4}=S_{p_{12} O_{2 t} p_{21}}=\pi\left(R_{2}^{2}+\delta\right) \frac{360^{\circ}-\left(\delta_{1}^{\circ}+\delta_{2}^{\circ}+\delta_{3}^{\circ}\right)}{360^{\circ}} .
\end{gathered}
$$

Area of the triangles:

$$
\begin{gathered}
S_{5}=S_{O_{e} O_{1 t 1} O_{2 t}}=\frac{1}{2}\left(O_{1 t 1} O_{2 t}\right)\left(O_{2 t} O_{1 t 2}\right) \sin \delta_{1} \\
S_{6}=S_{O_{e} O O_{2 t}}=\frac{1}{2}\left(O O_{2 t}\right)\left(O_{2 t} O_{e}\right) \sin \delta_{2} \\
S_{7}=S_{O O_{1 t 2} O_{2 t}}=\frac{1}{2}\left(O_{t 2} O\right)\left(O_{2 t} O_{1 t 2}\right) \sin \delta_{3}
\end{gathered}
$$

The total area of the working camera

$$
S=S_{1}-S_{2}-S_{3}-S_{4}-S_{5}-S_{6}-S_{7} .
$$

If all these areas are multiplied by the length of the rollers, we obtain approximately the corresponding volumes of the liquid (without taking into account the leakage through the gaps between the ends of the rollers and the walls of the body).

For parameters $R=120 \mathrm{~mm} ; R_{1}=40 \mathrm{~mm} ; R_{2}=29.6 \mathrm{~mm} ; e=10 \mathrm{~mm}$ and the width of the pump $100 \mathrm{~mm}$, the change in the working space of the working cameras is shown in Fig. 4. The calculations are made in Microsoft Excel software.

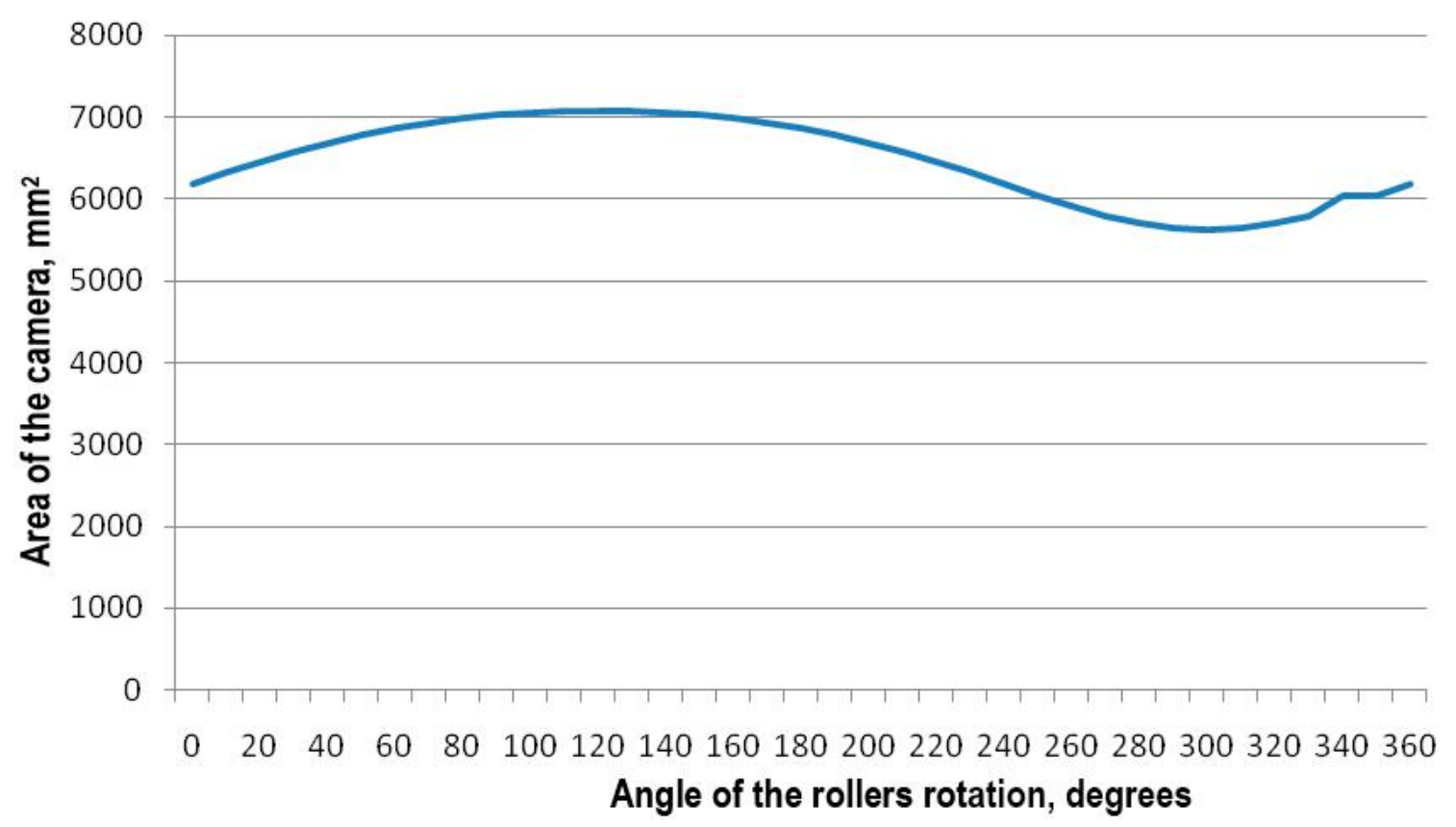

Fig. 5. Results of calculating the areas of working cameras

For testing, a pump model was created in the SolidWorks 2017 program. The model is shown in Fig. 6. Here a larger area (formed by working rollers) is highlighted in pink colour and a smaller one (formed by distributing rollers) - in blue. When the moving rollers of the pump are turning at $360^{\circ}$, we get a change of area. The result of the area change is shown in Fig. 7. Fig. 8 shows the scaled-up "blue" area. 


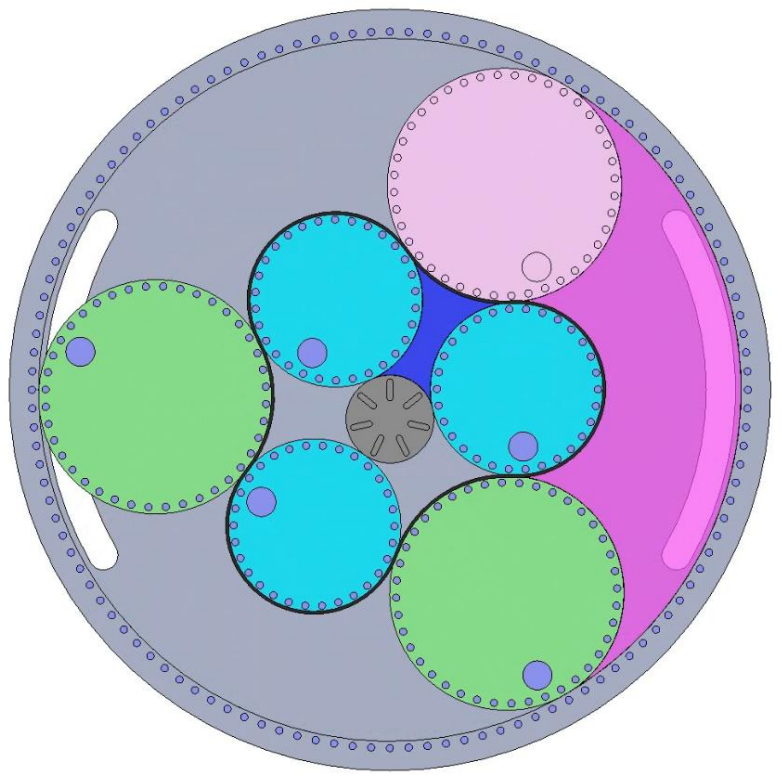

Fig. 6. Model of the pump in SolidWorks 2017

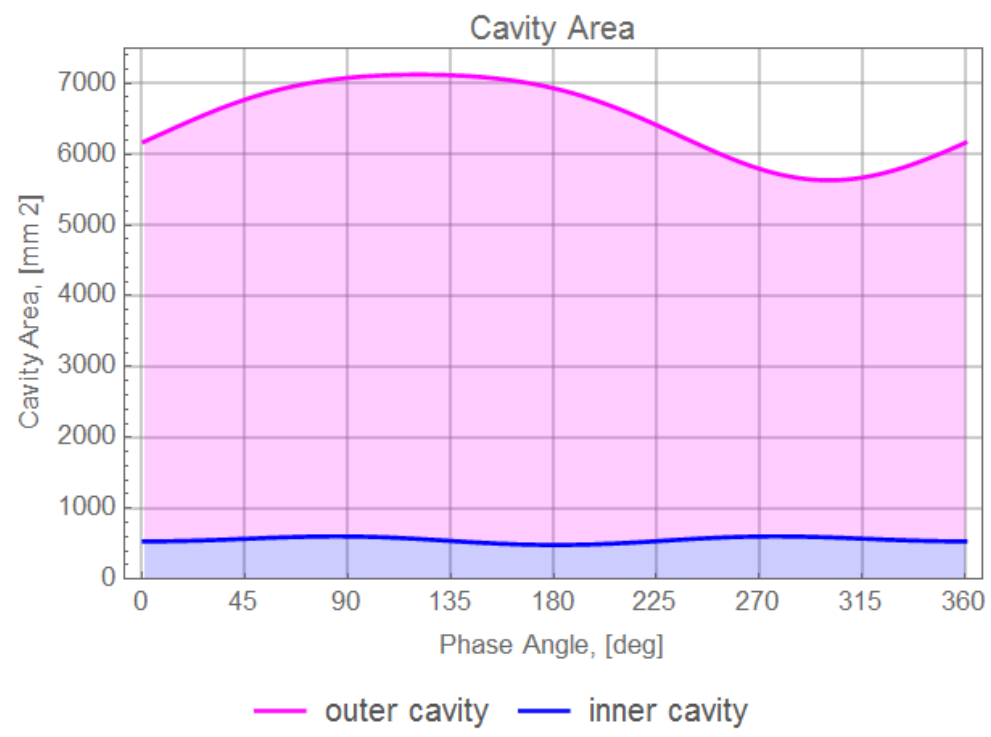

Fig. 7. Change of the working area of the pump defined in SolidWorks 2017

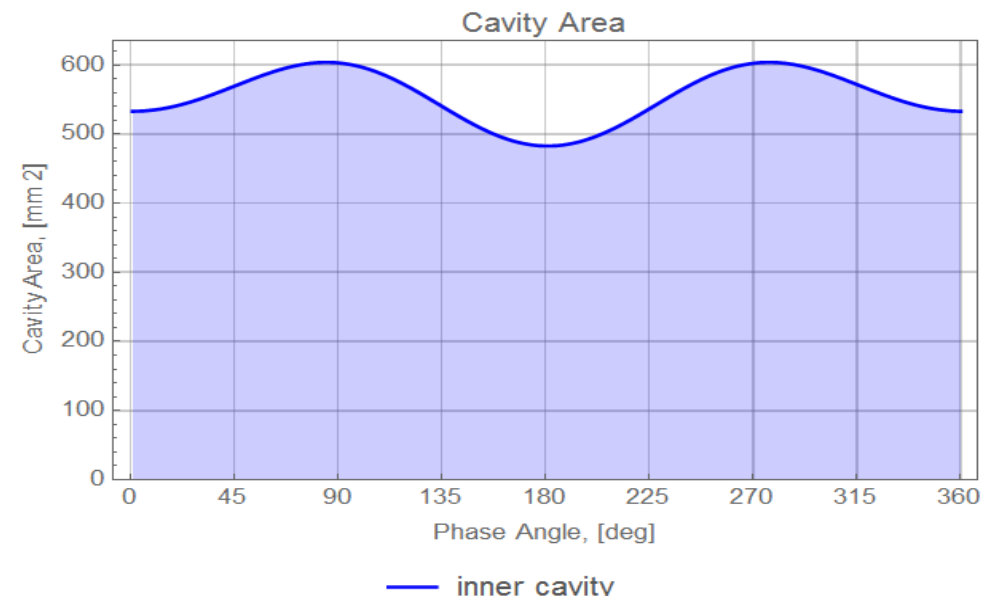

Fig. 8. Change of the small working area of the pump defined in SolidWorks 2017 
For these parameters, the compression ratio of the fluid was

$$
p=\frac{S_{\max }}{S_{\min }}=\frac{7122.13}{5631.2}=1.26 .
$$

The theoretical performance of the pump can be determined by the formula:

$$
Q_{H}=\Delta S_{T} \cdot \omega,
$$

where $\Delta S_{T}$ is the difference between maximum and minimum area.

The conditions for maintaining the pump's performance (see Fig. 9) are:

- the criterion for the existence of an S-ribbon

$$
\begin{aligned}
& \alpha_{1}+\alpha_{2}+\beta_{1}+\beta_{2}>2 \pi, \\
& \beta_{1}+\beta_{2}+\gamma_{1}+\gamma_{2}>2 \pi, \\
& \gamma_{1}+\gamma_{2}+\alpha_{1}+\alpha_{2}>2 \pi ;
\end{aligned}
$$

- the condition of the absence of contact between the tape and the guide roller

$$
R-2 R_{1}-\delta>r
$$

- the condition of the absence of contact between the rollers

$$
l_{O_{3} O_{3}}=\frac{\pi\left(R-R_{1}\right) \cdot \Delta}{180}>2 R_{1} .
$$

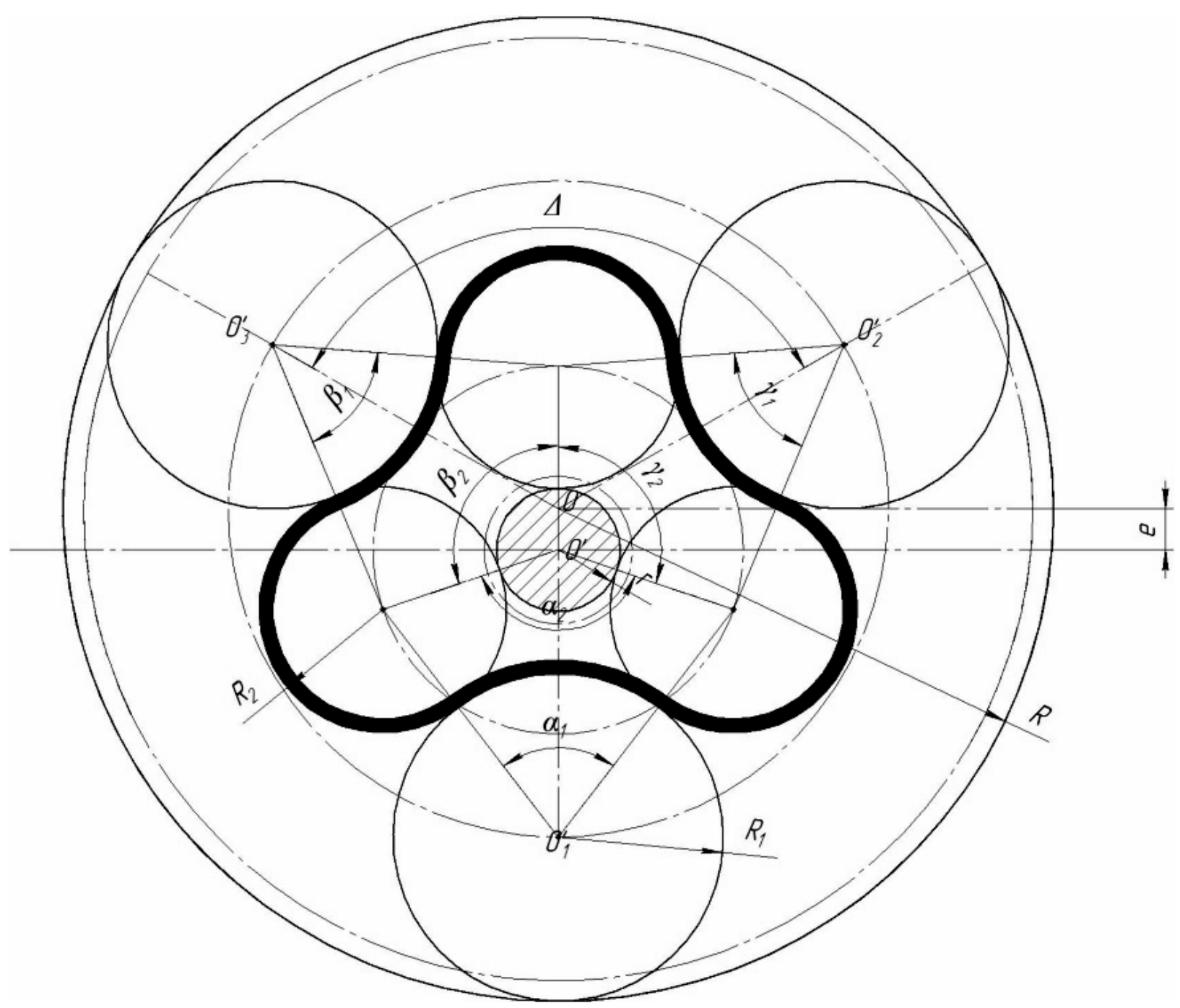

Fig. 9. Running position of the pump elements 


\section{Conclusions}

The conditions that ensure the efficiency of the mechanism are determined by the formulas 24-26. The principle of rational placement of inlet and outlet windows is shown. Areas and volumes of the cameras, when turning a ferromagnetic roller at $360^{\circ}$, are determined by the formulas $2-21$.

The proposed fundamentally new design of the pump makes it possible to get rid of the use of rotary supports outside the working area; simultaneously transfer two substances, as well as high efficiency coefficient by reducing sliding friction forces.

An additional advantage of this pump is that there is a process of liquid magnetization, which reduces the corrosion of the metal elements of the pump and the pipelines, significantly slows down the formation of scum and improves its removal that is relevant in the heat exchange systems, as well as reduces the deposition of resins and paraffin on the walls of oilfield equipment.

\section{References}

[1] I. A. Chinjaev, Rotornye nasosy [Rotary pumps]. Leningrad, Russia: Mashinostroenie Publ., 1969. [in Russian].

[2] K. A. Ibatulov, Gidravlicheskie mashiny i mehanizmy v neftjanoj promyshlennosti [Hydraulic machines and mechanisms in the oil industry]. Moscow, Russia: Nedra Publ., 1972. [in Russian].

[3] Norman Carlisle, "The Amazing Rolamite - It Opens the Door for 1000 Inventions", Popular Mechanics, vol. 129, no. 2, pp. 92-95, February 1968.

[4] M. S. Vorobiov, and D. P. Prokopenko, "Elektromahnitnyi hidronasos kochennia" ["Electromagnetic hydraulic pump of rotation"], UA Patent 108050, March 10, 2015. [in Ukrainian].

[5] L. B. Ganzburg and A. I. Fedotov, Proektirovanie jelektromagnitnyh i magnitnyh mehanizmov [Designing of electromagnetic and magnetic mechanisms]. Leningrad, Russia: Mashinostroenie Publ., 1980. [in Russian].

[6] D. F. Wilkes, “A new mechanism”, Mechanical Engineering, vol. 90, no. 4, pp. 11-29, April 1968.

[7] M. S. Vorobiov, V. I. Vekeryk, and O. A. Vorobiov,, "Rolykovyi lichylnyk" ["Roller counter"], UA Patent 68800, August 16, 2004. [in Ukrainian].

[8] Donald F. Wilkes, “Roller-Band Devices”, U.S. Patent 3452 175, June 24, 1969.

[9] K. Ragul'skis, R.-V. Ulozas, N. Bakaj, and A. Paljavichjus, Mehanizmy tipa rolamajt [Rolamite type mechanisms]. Vilnius, Lithuania: Mokslas Publ., 1990. [in Russian].

[10] A. K. Bubulis, L. R. Patashene, K. M. Ragul'skis and P.-V. K. Ulozas, "Nasos peristal'ticheskogo tipa" ["Pump of peristaltic type"], USSR Patent 649882, February 28, 1979. [In Russian].

[11] "Rolomite reduces friction in devices", Tribology, vol. 1, issue 2, pp. 71-73, March 1968.

[12] Chad English, and Donald Russell, "Implementation of variable joint stiffness through antagonistic actuation using rolamite springs", Mechanism and Machine Theory, vol. 34, issue 1, pp. 27-40, January 1999.

[13] George F. Anderson, and Alan A. Maris, "The Rolomite bracket: A preliminary discussion of frictionless tooth movement", Journal of Biomechanics, vol. 2, issue 2, pp. 199-201, May 1969.

[14] L. Ia. Ropiak, I. O. Shuliar, and O. M. Bohachenko, "Vplyv tekhnolohichnykh parametriv protsesu vidtsentrovoho armuvannia na pokaznyky yakosti detalei" ["Influence of technological parameters of centrifugal reinforcement upon quality indicators of parts"], Skhidno-Yevropeiskyi zhurnal peredovykh tekhnolohii [EasternEuropean Journal of Enterprise Technologies], vol. 1, no. 5 (79) pp. 53-62, 2016. [in Ukrainian]. 